\title{
Review on E-Waste Management and Recycling
}

\author{
Santhosh G1*, Sharma $\mathrm{S}^{1}$ and Nayaka GP2* \\ ${ }^{1}$ Department of Mechanical Engineering, NMAM Institute of Technology, India \\ ${ }^{2}$ Faculty of Metallurgical and Energy Engineering, Kunming University of Science and \\ Technology, China
}

\section{Review Article}

Volume 1 Issue 2

Received Date: October 05, 2018

Published Date: October 25, 2018

DOI: $10.23880 /$ oajwx-16000109

${ }^{*}$ Corresponding authors: Nayaka GP, Faculty of Metallurgical and Energy Engineering, Kunming University of Science and Technology, Kunming 650093, China, Email: valmikagp@rediffmail.com

Santhosh G, Department of Mechanical Engineering, NMAM Institute of Technology, India, Email: santhug099@gmail.com

\section{Abstract}

Electronic waste or e-waste is one of the quickly developing Problems of the world. E- Waste includes a huge number of parts, some containing toxic substances that can adversely affect human wellbeing and the earth, if not handled appropriately. In India, E-Waste management accepts more noteworthy criticalness not only due to the generation of its own E-Waste yet in addition on account of the dumping of E- Waste from developed nations. This is combined with India's absence of proper framework and techniques for its disposal and recycling. This review article gives a compact overview of India's present E- Waste situation, specifically magnitude of the ecological issue and wellbeing hazards, current disposal and recycling tasks.

Keywords: E-Waste; Disposal; Recycling

Abbreviations: WEEE: Waste Electrical and Electronic Equipment; EEE: Electrical and Electronic Equipment.

\section{Introduction}

Advancement of technological and extreme marketing of electrical and electronic equipment (EEE) throughout the world has increased the availability of electrical gadgets [1]. Usefulness of EEE majorly depends on its life cycle or arrival of newer version superior than the exiting one, Once EEE reaches their end of life or managed with the advanced version the disposed items are termed as "Waste Electrical and Electronic Equipment" [2]. E-Waste contains more than 1,000 unique substances, huge numbers of which are toxic, and makes genuine contamination upon disposal. These dangerous substances include lead, cadmium, mercury, plastics, and so on. In terms of production, internal utilization and gadgets trade enterprises have developed as the quickest developing section of Indian industry. Over the most recent five years, the Indian IT industry has recorded a CAGR (Compounded Annual Growth Rate) of in excess of 42.4 for each penny, which is twofold the development rate of IT enterprises in many of the developed nations. In the IT activity plan, the legislature had focused to expand the present level of entrance, from 5 for every 500 individuals to 1 for 50 individuals, in 2008 [3,4]. This visualizes applying IT in each stroll of the financial and social existence of the nation. At the point when contrasted with the USA, the Indian setup of 5 PCs for each 500 individuals does not speak to any indication of gigantic ascent in PCs oldness rate [5]. 
This figure speaks to a tremendous measure of hardware destined to be added to the waste stream as up gradation beyond a point becomes uneconomical and inconsistent with software in demand. Regardless, this intangibility has begun obscuring with the colossal import of garbage PCs that, in turn, make revolting circumstances for strong waste administration in India. The greatest wellspring of PC scrap are foreign nations that export huge amounts of PC waste as screens, printers, consoles, CPUs, typewriters, PVC wires, and so on. Subsequent to isolating every single residual segment, motherboards are put for open pit burning to separate the thin layer of copper foils laminated in the circuit board. Despite the fact that it is not really understood, E-Waste contains a switches blend of toxic substances, for example, lead and cadmium in circuit boards; lead oxide and cadmium in monitor cathode ray tubes (CRTs); mercury in switches and flat screen monitors; cadmium in PC batteries; polychlorinated biphenyls (PCBs) in older capacitors and transformers; and ruminated fire retardants on printed circuit boards, plastic housings, cables and polyvinyl chloride (PVC) cables protection that discharge very poisonous dioxins and furans when burned to recover copper from the wires [6]. Due to the hazards involved, disposing and recycling E-Waste has serious legal and environmental implications. These materials are complex and hard to reuse in an environmentally sound manner even in well-developed nations. The reusing of PC waste requires refined innovation and procedures, which are extremely costly, as well as need particular abilities and preparing for the task.

In India, the majority of the recyclers as of now occupied with reusing exercises don't have this costly innovation to deal with the waste. PC scrap is overseen through different administration choices, for example, item reuse, ordinary disposal in landfills, incineration and reusing. Waste Electrical and Electronic Equipment (WEEE) is getting to be one of the quickest developing waste streams around the world. E-Waste is a rising worldwide concern because of its alarmingly expanding volume and poisonous quality. Yet, the size of WEEE development has not been related to their gathering, reusing, renovating and reuse. Therefore, the life-cycle of WEEE is a straight movement with assembling, utilize, stockpiling and waste transfer. By crude reusing practices of casual area for the most part force a genuine risk to the earth and human wellbeing because of the extreme poisons discharge into air, soil and ground water [7]..

In numerous developing nations, especially low-wage and center wage nations, a noteworthy extent of E-Waste parts is discarded in unsanitary landfill destinations.
Similarly, informal E-Waste recycling is widely practiced. Wires are burned in open spaces to remove plastic and recover copper. Acid extraction and leaching techniques are also practiced retrieving precious metals like gold, platinum, palladium, selenium and silver from Printed Circuit Boards (PCBs) [8-10].

The anode sludge from the copper electrolysis process is subjected to pressure leaching, trailed by drying of the leach residue and the same after addition of fluxes is refined in a valuable metals heater, prompting the recuperation of selenium. The remaining material, basically silver, is cast into a silver anode, accordingly when subjected to a high-force electrolytic refining process, a high-purity silver cathode and anode gold ooze are framed while filtering of anode gold ooze prompts precipitation of high-immaculateness gold, and in addition palladium and platinum slime. Recovery of valuable metals from electronic pieces genuinely is the way to its business abuse by the reusing business, for profiteering; in the background of the way that e-scrap contains in excess of 40 times the grouping of gold substance in gold minerals found in the US, which is just about $33 \%$ the valuable metal recouped in e-waste handling [11-17]. The extraction of the valuable metal is completed by the entrenched strategies that are talked about in detail in different articles [18-21]. Different approaches, for example, pyro-metallurgy, hydrometallurgy, and bi-hydrometallurgy advancements are analyzed for the recuperation of gold and furthermore the assessment of recuperation proficiency of gold from ewaste has been reviewed [22].

Such practices can be found in countries such as China, India, Pakistan, Vietnam, the Philippines, Nigeria, and Ghana etc, where E-Waste is dissembled using rudimentary methods to recover valuable metals by people who lack the facilities to safeguard the environment and public health as show in Figure 1 below [8].

The two pertinent Directives on WEEE and Restriction of Hazardous Substances (RoHS) at first began in the middle of their preliminary stage as single directive, going for the diminishing the ecological effect of WEEE all inclusive. It is estimated that the global production of plastics approximately increased to nearly 12.8 million metric tons from 2013 to 2017, and expected to grow 50 million metric tons by 2018 with 4 to $5 \%$ growth rate per year [9]. At present India is fifth largest e-waste accumulating country in the world. Government of India took lot of measures to overcome the accumulation of 
WEEE by locating several E-Waste collection centers at each district of every state [6].

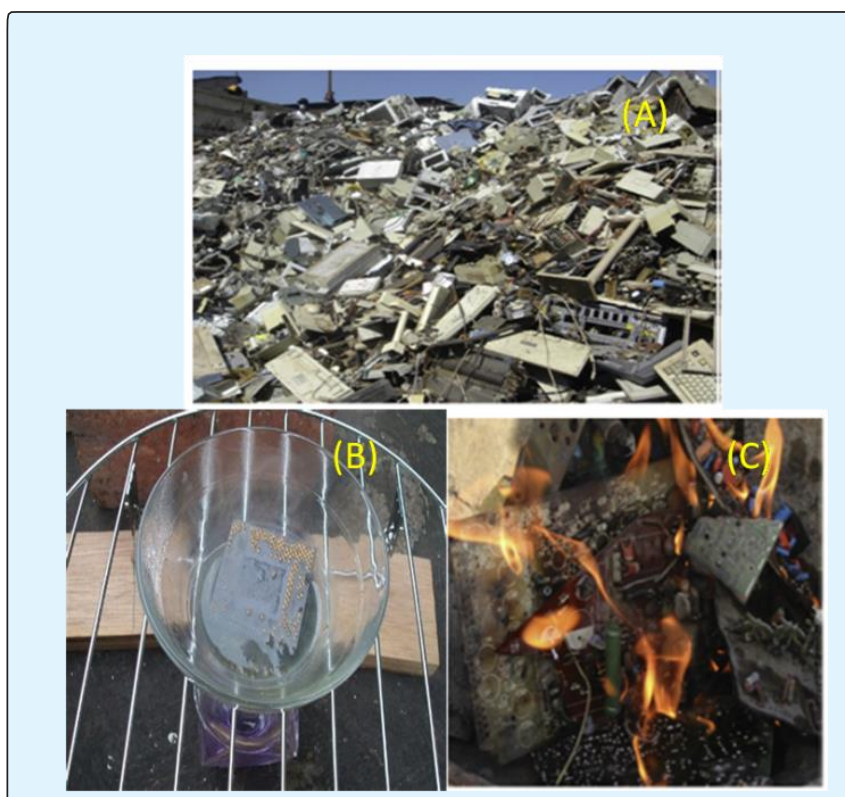

Figure 1: (a) E-Waste collection (b) Recovery of gold from waste PCB's using acid baths (c) Open burning of PCB waste.

Plastics in WEEE plastics are made of crude materials including oil, petroleum gas, carbon, basic salt and different items. At show, plastics are about totally gotten from petrochemicals created from fossil oil, of which around $4 \%$ is utilized for plastic generation at the worldwide level [10]. From the substance see point, plastics are manufactured materials with large scale subatomic structures, which can be recouped by the crude materials from which the plastics are initially made. It is assessed that the worldwide creation of plastics roughly expanded to about 600Mt from 2013 to 2017, and China remains the main plastics maker with $24.8 \%$ of the world's aggregate generation took after by Europe representing $20 \%$. Plastics, taking up around $20 \%$ of the aggregate WEEE, incorporate 5\% fire hindered plastics and $15 \%$ non-fire impeded plastics, as appeared in Figure 2 [7].

WEEE can be founded on 15 unique sorts of designing plastics, including acrylonitrile-butadiene-styrene (ABS), high affect polystyrene (HIPS), polyethylene (PE), polypropylene (PP), polystyrene (PS), styreneacrylonitrile (SAN), polyesters, polyurethane (PU), polyamide (PA), mixes of polycarbonate(PC)/ABS and mixes of HIPS/poly (p-phenyleneoxide) (PPO) [11]. As per an immediate investigation of describing the plastic constituents of WEEE, roughly 3400 things, including cooling machines, little WEEE, CPUs, replicating hardware, printers, CRT screens and CRT TVs were portrayed with the examination finding around $6000 \mathrm{~kg}$ of plastics with a few polymer composes.

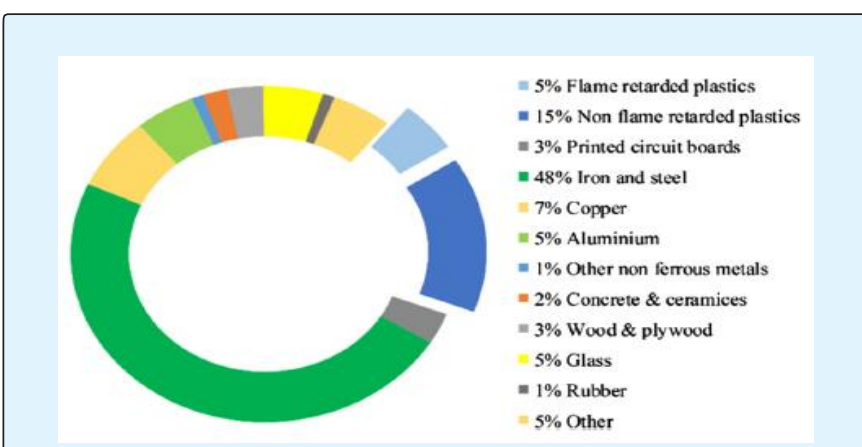

Figure 2: Average composition of WEEE [12].

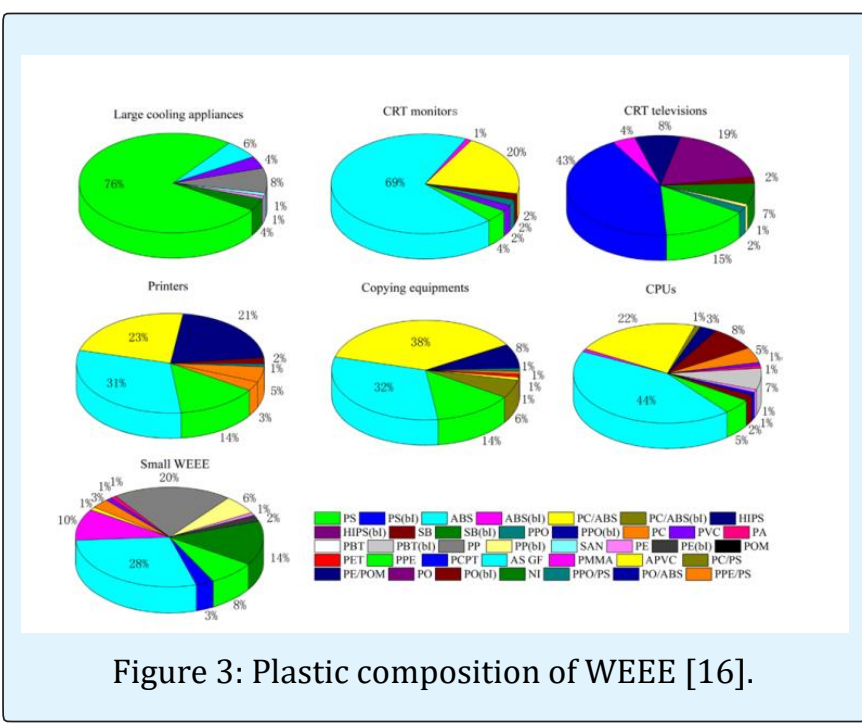

As a rule, the predominant polymers were observed to be PS, ABS, PC/ABS, HIPS and PP comes about that the mix of HIPS and ABS can represent around $55 \%$ of all WEEE plastics. Alongside this noteworthy assortment of materials, the various added substances (both natural and inorganic) are likewise added to plastics, for example, metals and Brominated Flame Retardants (BFRs), which would influence squander administration techniques because of their potential dangers [13]. The gadgets business represents the best utilization of BFRs, more than in autos or furniture. In PCs, BFRs are utilized fundamentally in the pcbs, connectors, plastic covers, and links. BFRs are additionally frequently utilized as a part of 


\section{Open Access Journal of Waste Management \& Xenobiotics}

plastic fronts of TVs and household kitchen apparatuses [14-16]. Figure 3 beneath demonstrates the Plastic synthesis exhibit in squander electrical and electronic gear (WEEE).

This review article provides an outline of the danger that e-wastes pose to mankind and environmental health from recycling and landfill disposals together with tools for the management of such wastes. The authors discussed case studies of e-waste recycling and management in order to promote effective reuse of the ewaste. This review article offers an overview of e-waste recycling, including a description of how it is generated and classified, strategies and technologies for recovering materials, and new scientific developments related to these activities. The authors discussed about the threat that e-waste pose to humankind and ecological wellbeing from reusing and landfill transfers together with tools for the management of such wastes.

\section{Conclusion}

India is placed in a very fascinating position. The need of an urgent approach to the e-waste hazard by technical and policy-level interventions, implementation and capacity building and increase in public awareness such that it can convert this challenge into an opportunity to show the world that India is ready to deal with future problems and can set global credible standards concerning environmental and occupational health. There is an increased focus from regulators towards the need for sustainable environment and the same is evidenced from the new Companies Act which requires certain companies to compulsorily carry out corporate social responsibility activities, including environmental development. In order to avoid adverse consequences such as revocation of authorization or prosecution, it is advisable that periodic internal audits and checks are conducted for identifying non-compliances and addressing them efficiently. Further, compliance with applicable environmental laws works to build brand image and product value, for acting in an environmentally responsible manner.

\section{References}

1. Nayaka GP, Manjanna J, Pai KV, Vadavi R, Keny SJ, et al. (2015) Recovery of valuable metal ions from the spent lithium-ion battery using aqueous mixture of mild organic acids as alternative to mineral acids. Hydrometallurgy 151: 73-77.

2. Nayaka GP, Pai KV, Santhosh G, Manjanna J (2016) Recovery of cobalt as cobalt oxalate from spent lithium ion batteries by using glycine as leaching agent. Journal of Environmental Chemical Engineering 4(2): 2378-2383.

3. Pinto VN (2008) E-waste hazard: The impending challenge. Indian Journal of Occupational and Environmental Medicine 12(2): 65-70.

4. Babu BR, Parande AK, Basha CA (2007) Electrical and electronic waste: A global environmental problem. Waste Management Resources 25(4): 307-318.

5. Brandon NP, Kelsall GH, Muller T, Olijve R, Schmidt M, et al. (2001) Metal recovery from electronic scrap by leaching and electro winning. In: Proc. $200^{\text {th }}$ Electrochemical Soc Meeting, San Francisco USA, 2-7 Sept 2001; Proc Electro Chem Soc, Energy and Electrochemical Processes for a Cleaner Environment, Electro Chem Soc NJ USA.

6. Nayaka GP, Zhang Y, Dong P, Wang D, Pai KV, et al. (2018) Effective and environmentally friendly recycling process designed for $\mathrm{LiCoO}_{2}$ cathode powders of spent Li-ion batteries using mixture of mild organic acids. Waste Management 78: 51-57.

7. Pathak P, Ranjan R, Srivastava, Ojasvic (2017) Assessment of legislation and practices for the sustainable management of waste electrical and electronic equipment in India. Renewable and Sustainable Energy 78: 220-232.

8. Ikhlayel M (2017) "Environmental impacts and benefits of state-of-the-art technologies for E-waste management", Waste Management 68: 458-474.

9. Wang R and Zhenming Xu (2014) Recycling of nonmetallic fractions from waste electrical and electronic equipment (WEEE): A review. Waste Management 34(8): 1455-1469.

10. Chuan Ma, Jie Yu, Wang B, Song Z, Xiang J, et al. (2016) Chemical recycling of brominated flame retarded plastics from e-waste for clean fuels production: A review. Renewable and Sustainable Energy Reviews 61: 433-450.

11. Cucchiella F, Adamo ID, LennyKoh SC, Rosa P (2015) Recycling of WEEEs: An economic assessment of present and future e-waste streams. Renewable and Sustainable Energy Reviews 51: 263-272. 


\section{Open Access Journal of Waste Management \& Xenobiotics}

12. (2001) Minnesota Office of Environmental Assistance, Recycling Used Electronics Report on Minnesota's Demonstration Project.

13. Buekens A, Yang J (2014) "Recycling of WEEE plastics: a review", Chemical Feedstock Recycling, pp: 10.

14. Stenvall E (2013) Electronic Waste Plastics Characterisation and Recycling by Melt-processing. Degree of licentiate of engineering, Chalmers university of technology Gothenburg, Sweden, pp: 162.

15. Tarantili PA, Triantou MI, Andreopoulos AG (2013) Recycling and Reuse of Plastics Contained in Waste from Electrical and Electronic Equipment (WEEE). School of Chemical Engineering, National Technical University of Athens, Athens, Greece pp: 25.

16. Markin C, Williams L (1980) Polypropylene/ABS Terpolymer Blends Mixing and Mechanical Properties. Journal of Applied Polymer Science 25(11): 2451-2466.

17. (2001) United States Geological Survey (USGS) Obsolete computers, "gold mine", or hightech trash?
Resources recovery from recycling. USGS Factsheet, FS-060-01.

18. Park YJ, Fray DJ (2009) Recovery of high purity precious metals from printed circuit boards. Journal of Hazardous Materials 164(2-3): 1152-1158.

19. Delfini M, Ferrini M, Manni A, Massacci P, Piga L (2011) Optimization of precious metal recovery from waste electrical and electronic equipment boards. Journal of Environmental Protection. 2: 675-682.

20. Fornalczyk A, Willner J, Francuz K, Cebulski J (2013) E-waste as a source of valuable metals. Archives of Materials Science and Engineering 63(2): 87-92.

21. Okwu PI, Onyeje IN (2014) Extraction of valuable substances from e-waste. American Journal of Engineering Research 3(1): 299-304.

22. Natesh PP, Govindaradjane S, Kumar SP (2015) Methodological review on recovery of gold from ewaste in India. Journal of Chemical and Pharmaceutical Sciences 8(2): 268-272. 